\title{
The ability of emergency physicians to diagnose and score acute pancreatitis on computed tomography: authors' response
}

\author{
A. Karagöz ${ }^{1}$ E. E. Ünlüer ${ }^{2}$
}

Received: 7 September 2017 / Accepted: 16 September 2017 / Published online: 16 October 2017

(C) Springer-Verlag GmbH Germany 2017

\section{Dear Editor,}

I read the letter from A.C. Ariffin et al. with great interest. Thanks for their interest in our article. As they mentioned in their letter, positive findings for acute pancreatitis (AP) on computed tomography (CT) is one of the three diagnostic criteria for AP [1]. So, CT is still an important imaging modality for the diagnosis of AP.

We have also mentioned in our article that American College of Gastroenterology (ACG) guidelines do not recommend the routine use of contrast-enhanced CT (CECT) in patients with AP and recommends the use of CECT for the patients for whom the diagnosis is unclear or who fail to improve clinically within the first $48-72 \mathrm{~h}$ of admission [2, 3], but as different studies have noted and we have faced in our clinical daily routine, the majority of patients underwent CECT in the emergency department (ED) or within $24 \mathrm{~h}$ of admission [3, 4]. Most of the CECTs are interpreted by Emergency Physicians (EPs) initially in our ED especially in nightshifts. We aimed to evaluate this problem that we

This is a reply to a Letter to the Editor available here: doi:10.1007/s00068-017-0843-1.

This reply and the corresponding Letter to the Editor refer to the article available at doi:10.1007/s00068-016-0743-9.

A. Karagöz

dr.akaragoz@hotmail.com

E. E. Ünlüer

erolerdenun@yahoo.com

1 Department of Emergency Medicine, İzmir Çiğli Training Hospital, 35620 Çiğli/izmir, Turkey

2 Department of Emergency Medicine, Faculty of Medicine, Uşak University, 64000 Uşak, Turkey routinely encountered in a scientific way and see that our interpretations made by EPs are sufficient or not in our article. The indications for early CECT are beyond the topic of our article.

\section{Compliance with ethical standards}

Conflict of interest All of the authors declare that the manuscript, as submitted or its essence in another version, is not under consideration for publication elsewhere, and will not be published elsewhere while under consideration by European Journal of Trauma and Emergency Surgery. All authors have made substantive contributions to the study, and all authors endorse the data and conclusions. A single study is not split up into several parts to increase the quantity of submissions and submitted to various journals or to one journal over time. No data have been fabricated or manipulated (including images) to support our conclusions. No data, text, or theories by others are presented as if they were the authors' own.

\section{References}

1. Ariffin AC, Ngadiron H. Acute pancreatitis: is early CT necessary? Eur J Trauma Emerg Surg. 2017. doi:10.1007/s00068-017-0843-1.

2. Karagöz A, Ünlüer EE, Oyar O, Topal FE, Topal F. The ability of emergency physicians to diagnose and score acute pancreatitis on computed tomography. Eur J Trauma Emerg Surg. 2017;43:287-92.

3. Tenner S, Bailie J, DeWitt J, Vege SS. American College of Gastroenterology. American College of Gastroenterology guideline: management of acute pancreatitis. Am J Gastroenterol. 2013;108:1400-15.

4. Papachristou GI, Clermont G, Sharma A, Yadav D, Whitcomb DC. Risk and markers of severe acute pancreatitis. Gastroenterol Clin N Am. 2007;36:277-96. 